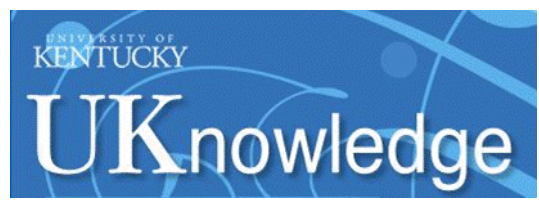

University of Kentucky

UKnowledge

$10-23-2020$

\title{
Toward a Century of Language Attitudes Research: Looking Back and Moving Forward
}

\author{
Marko Dragojevic \\ University of Kentucky, marko.dragojevic@uky.edu \\ Fabio Fasoli \\ University of Surrey, UK \\ Jennifer Cramer \\ University of Kentucky, jennifer.cramer@uky.edu \\ Tamara Rakić \\ Lancaster University, UK
}

Follow this and additional works at: https://uknowledge.uky.edu/comm_facpub

Part of the Anthropological Linguistics and Sociolinguistics Commons, and the Communication

Commons

Right click to open a feedback form in a new tab to let us know how this document benefits you.

\section{Repository Citation}

Dragojevic, Marko; Fasoli, Fabio; Cramer, Jennifer; and Rakić, Tamara, "Toward a Century of Language

Attitudes Research: Looking Back and Moving Forward" (2020). Communication Faculty Publications. 23. https://uknowledge.uky.edu/comm_facpub/23

This Article is brought to you for free and open access by the Communication at UKnowledge. It has been accepted for inclusion in Communication Faculty Publications by an authorized administrator of UKnowledge. For more information, please contact UKnowledge@lsv.uky.edu. 


\section{Toward a Century of Language Attitudes Research: Looking Back and Moving Forward}

Digital Object Identifier (DOI)

https://doi.org/10.1177/0261927X20966714

Notes/Citation Information

Published in Journal of Language and Social Psychology, v. 40, issue 1.

(C) The Author(s) 2020

The copyright holder has granted the permission for posting the article here.

The document available for download is the authors' post-peer-review final draft of the article. Citation of the final published version is as follows:

Dragojevic, M., Fasoli, F., Cramer, J., \& Rakić, T. (2021). Toward a century of language attitudes research: Looking back and moving forward. Journal of Language and Social Psychology, 40(1), 60-79.

https://doi.org/10.1177/0261927X20966714 


\title{
Toward a Century of Language Attitudes Research:
}

\section{Looking Back and Moving Forward}

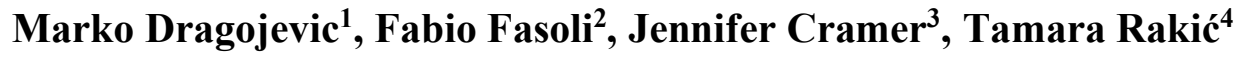

\begin{abstract}
The study of language attitudes is concerned with the social meanings people assign to language and its users. With roots in social psychology nearly a century ago, language attitudes research spans several academic disciplines and draws on diverse methodological approaches. In an attempt to integrate this work and traverse disciplinary boundaries and methodological proclivities, we propose that language attitudes — as a unified field — can be organized into five distinct — yet interdependent and complementary_-lines of research: documentation, explanation, development, consequences, and change. After highlighting some of the key findings that have emerged from each area, we discuss several opportunities and challenges for future research.
\end{abstract}

\section{Keywords}

language attitudes, language variety, language, accent, voice

${ }^{1}$ Department of Communication, University of Kentucky, USA

${ }^{2}$ School of Psychology, University of Surrey, UK

${ }^{3}$ Department of Linguistics, University of Kentucky, USA

${ }^{4}$ Psychology Department, Lancaster University, UK

\section{Corresponding Author:}


Marko Dragojevic, Department of Communication, University of Kentucky, 238 Blazer Dining,

Lexington, KY 40506; email: marko.dragojevic@uky.edu 
The study of language attitudes is concerned with the social meanings people assign to language and its users. The social-scientific study of language attitudes has roots in social psychology and spans nearly a century. In the 1930s, several researchers sought to test whether people could make reliable and accurate judgments about speakers' personality based on voice alone (e.g., Allport \& Cantril, 1934; Pear, 1930). Four main findings emerged from this early research: (1) people do make voice-based judgments about others; (2) judgements about speakers' social group memberships (e.g., sex, social class) can be remarkably accurate, when compared to objective criteria; (3) judgments about speakers' personality traits are largely inaccurate, when compared to speakers' self-ratings; and (4) irrespective of accuracy, there is remarkable consistency in people's judgments, suggesting that they reflect social stereotypes. This led to the conclusion that there was little advantage in pursuing voice as a reliable cue to actual personality, and this research was rendered relatively silent until the 1960s (for parallels in perceptual dialectology, see Preston, 1989). That decade saw an important methodological advancementnamely, Lambert et al.’s (1960) introduction of the matched-guise technique - as well as diffusion of interest in people's evaluative reactions to language (irrespective of accuracy) to other fields, most notably linguistics (Hoenigswald, 1966; Labov, 1966). Together, this provided the impetus for hundreds of language attitudes studies worldwide, which continue to this day (Giles \& Watson, 2013).

Since its inception in 1982, the Journal of Language and Social Psychology (JLSP) has provided and continues to provide an important outlet for language attitudes research (Giles, in press). As part of this $40^{\text {th }}$ Anniversary Special Issue of the $J L S P$, we provide a succinct, integrative overview of the language attitudes field, bringing together the diverse crossdisciplinary research that has been conducted on this topic, cross-culturally and worldwide. In 
what follows, we first define the language attitudes construct. Then, we provide a brief overview of the main methodologies used in the field. Next, we introduce a heuristic framework that organizes the field into five distinct, but closely related, lines of research, and highlight some of the key findings that have emerged from each. Finally, we discuss several opportunities and challenges for future research.

\section{The Language Attitudes Construct}

Social psychologists generally agree that an attitude is an evaluative reaction to an object (e.g., person, place; Albarracin \& Shavitt, 2018). In line with this view, we define language attitudes as evaluative reactions to language. ${ }^{1}$ There is less agreement within social psychology, however, about the structure of attitudes, which have variably been equated with cognition, affect, and behavior (see Fazio \& Olson, 2003). One conceptualization - the expectancy-value model (Fishbein \& Ajzen, 1975) — holds that attitudes are a function of people's salient beliefs about an attitude object (e.g., Italian is beautiful) and their evaluations of those beliefs (e.g., beautiful is good) (but see Fazio \& Olson, 2003). Language attitude scholars have predominantly adopted this perspective, and the study of language attitudes has largely been the study of evaluative beliefs (but see, for example, Cargile \& Giles, 1997).

Evaluative beliefs about language can be divided into two main types: beliefs about different language varieties and beliefs about speakers of different language varieties. Beliefs about language coalesce along three main evaluative dimensions: structure (e.g., logical), value (e.g., pleasant), and sound (e.g., soft) (Schoel et al., 2013). Beliefs about speakers, much like

\footnotetext{
${ }^{1}$ The object of language attitudes is language in its spoken, written, and signed forms. However, extant research has almost exclusively focused on attitudes to spoken language (but see Gibbons et al., 1991).
} 
person perception more generally (Fiske et al., 2002), coalesce along two main evaluative dimensions: status (e.g., competent) and solidarity (e.g., warm) (Ryan, 1983; for additional dimensions, see Zahn \& Hopper, 1985). People's beliefs about language and about speakers are closely related. For instance, beliefs about language structure correlate strongly with beliefs about speakers' status, whereas beliefs about language sound correlate strongly with beliefs about speakers' solidarity. Also, both types of beliefs are equally strongly correlated with general measures of language attitudes (Schoel et al., 2013). Most language attitude research has focused on people's evaluative beliefs about speakers, and the present article reflects this bias.

\section{Methodology}

Language attitudes have been studied using three main approaches: direct, indirect, and societal treatment (Garrett, 2010). The direct approach involves explicitly asking respondents to report their language attitudes, typically through surveys or interviews. For instance, participants may be presented with a list of language varieties (e.g., French) and/or speakers of those varieties (e.g., French speakers) and asked to rate each using evaluative trait scales (e.g., Coupland \& Bishop, 2007). In lieu of predetermined labels, perceptual dialectologists frequently present participants with a map of a particular geographic area (e.g., the US) and ask them to label where different varieties are spoken and/or to provide open-ended descriptions or rate on evaluative characteristics (e.g., correct, pleasant) the language spoken in different areas (e.g., each USA state) (e.g., Cramer \& Montgomery, 2016).

The indirect approach also involves asking respondents to report their language attitudes, but in more subtle ways. The dominant method in this approach is the speaker evaluation paradigm, in which participants listen to a series of audio-recorded voices or "guises"- 
representing different language varieties — and evaluate each using evaluative trait scales (e.g., Lambert et al., 1960), open-ended questions (e.g., Campbell-Kibler, 2011), or other methods (e.g., Kinzler et al., 2009). The different guises can be produced by the same multilingual or multidialectical speaker authentically rendering the target varieties (i.e., matched-guise technique: Lambert et al., 1960) or by different speakers, each speaking in their habitual language variety (i.e., verbal-guise technique: Tucker \& Lambert, 1969). Other methods falling under the indirect approach include various versions of the implicit association task (e.g., McKenzie \& Carrie, 2018).

In societal treatment approaches, participants are not asked to report their language attitudes. Instead, researchers engage in direct observation or analyze existing language attitude "artifacts" (e.g., media portrayals of different linguistic groups) to infer language attitudes. Methods falling under this approach include ethnography (e.g., Hammine, 2020), discourse analysis (e.g., Liebscher \& Dailey-O’Cain, 2009), and content analysis (e.g., Dobrow \& Gidney, 1998).

\section{Language Attitudes as a Unified Field: Core Research Foci}

The language attitudes literature spans several disciplines_-including social psychology, linguistics, communication, and (linguistic) anthropology — and, as illustrated above, draws on a diverse array of methodologies. In an attempt to integrate this work and traverse disciplinary boundaries and methodological proclivities, we propose that language attitudes - as a unified field — can be organized into five distinct — yet interdependent and complementary — lines of research: documentation, explanation, development, consequences, and change. Past reviews have relied on various frameworks to organize the filed, ranging from methodological (Garrett, 
2010) to geographical (Giles \& Watson, 2013). By placing emphasis on the core lines of research pursued by language attitudes scholars - and glossing over disciplinary and methodological distinctions - the conceptual framework presented here offers another heuristic lens through which to view and organize the field (see also Dragojevic, 2018). In what follows, we highlight some of the key findings that have emerged from each line of research and describe how the different research areas relate to and complement one another.

\section{Documentation}

The predominant and longest-standing line of research has focused on documenting people's attitudes toward different language varieties and the speakers who use them; this research is primarily descriptive. Past studies have documented people's attitudes toward a wide range of linguistic variation, including different languages (e.g., Lambert et al., 1960); regional (e.g., Kinzler \& DeJesus, 2013), ethnic (e.g., Rodriguez et al., 2004), and social-class accents and dialects (e.g., Giles, 1970); foreign accents (e.g., Lindemann, 2003); code-switching (e.g., Genesee \& Bourhis, 1982); gay and lesbian speech (e.g., Fasoli \& Hegarty, 2020); powerful/powerless language (e.g., Gibbons et al., 1991); lexical formality (e.g., Levin et al., 1991) and diversity (e.g., Bradac \& Wisegarver, 1984); as well as individual linguistic variables (e.g., Labov, 1966).

Collectively, this research shows that language varieties within a given society can be ordered on a hierarchy of prestige, typically corresponding to the socioeconomic status of the social groups they are associated with. Varieties associated with socioeconomically dominant groups tend to carry high prestige; these typically include majority group languages, standard varieties — namely those that have been codified (Milroy \& Milroy, 1999) — and other forms 
associated with powerful groups (e.g., straight speech) (hereafter high prestige varieties). In contrast, varieties associated with socioeconomically subordinate groups tend to carry low prestige; these typically include minority group languages, nonstandard varieties — namely those that diverge from codified norms, including most regional and ethnic dialects and foreign accents - and other forms linked to stigmatized groups (e.g., gay/lesbian speech) (hereafter low prestige varieties).

Cross-culturally and worldwide, speakers of low prestige varieties are typically rated less favorably on status traits than speakers of high prestige varieties (Fuertes et al., 2012; Preston, 1989). Some low prestige varieties are denigrated more than others (Coupland \& Bishop, 2007; Lindemann, 2005), and the more a person's speech diverges from high prestige forms, the less status they tend to be attributed (Dragojevic et al., 2017). This evaluative downgrading can occur in both formal (e.g., school) and informal (e.g., home) contexts, but is typically accentuated in the former (Creber \& Giles, 1983). It also tends to emerge regardless of listeners' own group affiliations; when differences do emerge, they tend to be differences in degree of preference rather than direction of preference (Woolard \& Gahng, 1990). Indeed, speakers of low prestige varieties themselves often ascribe low status to members of their own linguistic communities (Kinzler \& DeJesus, 2013) and, sometimes, may even exaggerate it, reflecting what has been termed the "minority group reaction" (Lambert et al., 1960) and "linguistic insecurity" (Labov, 1966).

Despite this, speakers of low prestige varieties are sometimes rated more favorably on solidarity traits than speakers of high prestige varieties by members of their own linguistic community (Luhman, 1990) or more widely (Kinzler \& DeJesus, 2013). This covert prestige (Labov, 1966), however, does not extend to all low prestige varieties (Coupland \& Bishop, 2007) 
nor does it extend necessarily to all speakers of a given variety (Gallois et al., 1984; Luhman, 1990). Indeed, low prestige varieties — especially foreign accents — are often downgraded on both dimensions (Cramer, 2016).

\section{Explanation}

The documentation literature has provided clear evidence that language attitudes occur in nonrandom ways. In an attempt to explain these empirical regularities, another line of research has focused on identifying the causal mechanisms that underlie language attitudes. In this way, the documentation literature — although itself primarily descriptive — has served as an important springboard for theoretical development (see Giles \& Marlow, 2011).

In their seminal work, Lambert et al. (1960) reasoned that language attitudes reflect social group stereotypes. Consistent with this proposition, extant research shows that evaluative reactions to language are often based on learned stereotypic associations rather than any inherent properties of language itself (Giles \& Niedzielski, 1998). Members of different social groups speak differently (Labov, 1966). People become aware of these associations at a young age and use language to infer speakers' social group memberships (e.g., ethnicity, social class; Kinzler et al., 2010). Although social categorization can be based on any socially diagnostic cue, spoken language often assumes primacy over other cues. For instance, both adults and children are more likely to categorize others based on accent than race-related visual cues (Kinzler et al., 2009; Rakić et al., 2011a).

Once a social category becomes salient, associated stereotypes are activated and influence person perception (Dragojevic, 2018). Stereotype content typically reflects the sociostructural relations between groups in society (Fiske et al., 2002). Status stereotypes are based on 
perceived socioeconomic status (Ryan, 1983). Consequently, speakers categorized as belonging to socioeconomically subordinate groups (e.g., speakers of low prestige varieties) are typically attributed less status than speakers categorized as belonging to socioeconomically dominant groups (e.g., speakers of high prestige varieties). Solidarity stereotypes are based on ingroup loyalty (Ryan, 1983) and perceived competition (both realistic and symbolic: Kervyn et al., 2015). Consequently, speakers categorized as belonging to one's linguistic ingroup and noncompetitive outgroups (e.g., some regional accented-speakers) are typically attributed more solidarity than speakers categorized as belonging to competitive outgroups (e.g., most foreignaccented speakers). The tendency to ascribe high solidarity to members of one's own linguistic community is especially pronounced among people who identify strongly with that community (Luhman, 1990) and perceive it to have increasing vitality (i.e., status, demographics, institution support; Ryan et al., 1984).

Language-based social categorization and stereotyping are prone to considerable variation, for several reasons. First, most linguistic cues mark multiple identities, at various levels of specificity (see also notion of indexical fields: Eckert, 2008). For instance, a New York accent marks a local identity (New York), a regional identity (East Coast), and a national identity (American), among others. Which identity becomes salient depends on listeners' familiarity with the associations in question (Ryan, 1983) as well as the social comparative context in which social categorization occurs (Abrams \& Hogg, 1987). Second, at all levels of specificity, listeners can make errors. Errors are more likely to occur for more specific social categories (e.g., Korean vs. Chinese) than abstract categories (e.g., native vs. nonnative) (Lindemann, 2003). This variation in categorization can be consequential. To the extent that different social categories are associated with different stereotypes, then the same speaker can be evaluated 
differently depending on how they are categorized (Dragojevic et al., 2018; Yook \& Lindemann, 2013), with consequences for how listeners subsequently perceive and process their speech (McGowan, 2015; Rubin, 1990). Third, in addition to inferring which groups speakers belong to, listeners also use language to gauge how prototypical of those groups speakers are (Dragojevic et al., 2017) which, in turn, can influence the extent to which speakers are stereotyped (Blair et al., 2002). Fourth, listeners' perceptions of the socio-structural relations between different groups in society - and their stereotypes of those groups - can vary as a function of listeners' own group affiliations. Consequently, even though different groups of listeners may categorize a speaker identically, they may evaluate the speaker differently (Coupland \& Bishop, 2007; Gallois et al., 1984).

Neither the activation of a specific social category nor knowledge of specific linguistic stereotypes, however, is necessary to evoke language attitudes. For instance, infants express a clear social preference for native- over foreign-language speakers, without any knowledge of specific linguistic stereotypes (Kinzler et al., 2007). This preference is likely based on familiarity. Related, people may form value judgments about specific linguistic features (e.g., double negative are illogical), without necessarily having any knowledge of how those features are distributed socially. In this way, language may elicit evaluative reactions in a more direct fashion (see Roessel et al., 2017).

Language attitudes can also be influenced by listeners' processing fluency, defined as the subjective ease or difficulty listeners experience processing a person's speech (Dovidio \& Gluszek, 2012). Listeners' processing fluency can be influenced by various factors, including speakers' language (Cristia et al., 2012); environmental factors, such as background noise (Munro, 1998); and listeners' own characteristics, such as their familiarity with the variety in 
question (Gass \& Varonis, 1984) and their social dominance orientation (Hansen \& Dovidio, 2016). Disruptions in fluency_regardless of source — can negatively bias listeners' evaluations of speakers (Dragojevic \& Giles, 2016; Roessel et al., 2019), and these effects persist even after controlling for categorization and stereotyping (see fluency principle: Dragojevic, 2020;

Dragojevic et al., 2017).

Listeners' expectations can also play a role. Prior to hearing a person speak, listeners may form expectations about the person's likely language behavior, typically based on contextual norms and/or social group stereotypes (Burgoon, 1993). Compared to speakers who confirm listeners' expectations, speakers who negatively violate expectations (i.e., use a less prestigious variety than expected) engender more negative evaluations, whereas speakers who positively violate expectations (i.e., use a more prestigious variety than expected) engender more positive evaluations (for norm-based violations, see Creber \& Giles, 1983; for stereotype-based violations, see Hansen et al., 2018).

\section{Development}

Given overwhelming empirical evidence showing that language attitudes are socially mediatedand therefore potentially prone to variation across the lifespan-researchers have also focused their attention on the developmental trajectory of language attitudes, examining when, how, and from whom language attitudes are acquired. This research shows that perceptual sensitivity to linguistic variation begins at birth. Newborns can distinguish between their maternal language and foreign languages (Mehler et al., 1988). By the time they are 5 months old, infants look longer at linguistic ingroup than linguistic outgroup members and can distinguish between native and foreign accents (Kinzler et al., 2007), as well as some regional varieties of their maternal 
language (Butler et al., 2011). The first clear social preferences based on language emerge as early as 10-12 months after birth. For instance, infants at this age are more likely to accept toys from native over foreign language speakers (Kinzler et al., 2007).

This preference for linguistic ingroup members continues into early childhood and extends to other domains. Preschoolers preferentially select native-language and native-accented speakers as friends and trust them more over foreign-language and foreign-accented speakers, respectively (Kinzler et al., 2007; Kinzler et al., 2011). Preschoolers also begin to coordinate linguistic and social knowledge. For instance, they assume that people who speak an unfamiliar foreign language are more likely to be of a different race, dress differently, and live in a different style of housing than people who speak their native language (Hirschfield \& Gelman, 1997). They also begin to make language-based judgments about others' personality traits (e.g., how smart and nice they are; Kinzler \& DeJesus, 2013). Initially, these judgments continue to favor linguistic ingroup members, even if they are associated with negative stereotypes (Day, 1982). However, by the first few years of elementary school, most children endorse the same linguistic stereotypes as adults: They evaluatively upgrade on relevant dimensions speech they associate with positive stereotypes, regardless of whether it is their own (Kinzler \& DeJesus, 2013).

Children can acquire specific linguistic stereotypes through exposure to both overt and covert messages about language. Overt messages explicitly assign value to language (e.g., double-negatives are illogical) and its users (e.g., people who use double-negatives are uneducated). Such messages are prevalent in the educational system, where high prestige varieties typically function as the code of instruction and are explicitly prescribed and promoted as the "best" and most "correct" ways to speak (Milroy \& Milroy, 1999). Equally overt messages 
can also come from parents, peers, and other community members across various contexts (Marlow \& Giles, 2010).

Covert messages implicitly link value to language. For instance, the visibility and salience of different varieties in the public sphere - or the linguistic landscape (Landry \& Bourhis, 1984) — can lead people to make inferences about the value and power of those varieties and the groups they are associated with (Dailey et al., 2005). Media portrayals contribute to these perceptions. For instance, standard speakers are overrepresented in the media, whereas nonstandard speakers are underrepresented, which can undermine the perceived status of the latter (Lippi-Green, 2012). Moreover, media portrayals of different linguistic groups are stereotypical: Standard speakers tend to be portrayed in positive roles, whereas nonstandard speakers - particularly foreign-accented speakers - in negative roles. Such stereotypical portrayals have been documented in Disney movies (Lippi-Green, 2012), children's cartoons on cable and network television (Dobrow \& Gidney, 1998), and American primetime television (Dragojevic et al., 2016). Repeated exposure to these stereotypical portrayals can contribute both to the formation and maintenance of language-based stereotypes (Mastro, 2009).

\section{Consequences}

Complementing the documentation literature described earlier, researchers have also afforded attention to the social and behavioral consequences of language attitudes. Whereas documentation studies treat language attitudes as the key output of interest, studies focused on consequences treat language attitudes as socially meaningful input that influences subsequent responses. Stated differently, language attitudes are assumed to mediate the effects of linguistic 
variation on these more distal outcomes, though admittedly this assumption is only rarely tested explicitly (e.g., Fasoli \& Hegarty, 2020; Roessel et al., 2019).

Language attitudes have been shown to influence language learning and maintenance (Gardner, 1982), as well as language choice during interpersonal and intergroup encounters (Bourhis, 1984). They have also been shown to influence nonlanguage behaviors and other social judgments across a range of applied contexts. Collectively, this research shows that speakers of low prestige varieties frequently face prejudice and discrimination (see Gluszek \& Dovidio, 2010b; Roessel et al., 2020). For instance, nonstandard speakers tend to be judged as less suitable than standard speakers for high status employment (e.g., manager; Giles et al., 1981; Rakić et al., 2011b). This effect tends to be more pronounced the stronger a speaker's nonstandard accent is (Carlson \& McHenry, 2006) and can emerge regardless of speakers' actual qualifications (Roessel et al., 2019). Similarly, gay- and lesbian-sounding speakers are judged as less suitable for leadership positions than straight-sounding speakers because they are attributed less status (Fasoli \& Hegarty, 2020). In educational settings, students often rate nonnativeaccented instructors less favorably than native-accented instructors on teaching quality and effectiveness (Gill, 1994; Subtirelu, 2015)_even when they themselves are nonnative speakers (Hendriks et al., 2018) — and may actively avoid courses taught by nonnative-accented instructors (Rubin \& Smith, 1990). Educators may also display prejudice and make more negative inferences about the academic performance and future prospects (e.g., happiness) of nonstandard-speaking students (Choy \& Dodd, 1976).

In simulated criminal proceedings, nonstandard speakers are often judged as more guilty than standard speakers of both blue-collar (e.g., assault) and white-collar crimes (e.g., fraud) (Dixon et al., 2002; Dixon et al., 1994), and as more likely to be re-accused of a crime, 
regardless of the quality of evidence presented against them (Dixon \& Mahoney, 2004). They also tend to be judged as less credible, truthful, and accurate eyewitnesses (Frumkin, 2007). Moreover, nonstandard speakers are typically perceived as less persuasive (Dragojevic et al., 2020; Tsalikis et al., 1991) and are less likely to secure compliance than standard speakers (Bourhis \& Giles, 1976; Giles et al., 1975). The former effect, however, may be attenuated or even reversed when nonstandard speakers advocate positions incongruent with listeners' expectations (Giles et al., 1995).

\section{Change}

In light of the wide range of adverse consequences negative language attitudes can have for those involved, researchers have also devoted some effort to developing and assessing the effectiveness of various interventions designed to counteract those negative effects. Although research in this area is relatively scarce, both macro-institutional and individual-based interventions appear to have promise. Some studies have examined how government language policies influence language attitudes over time. This research shows that such policies can have significant effects on the vitality of different linguistic groups in society (Bourhis, 2019) which, over time, can enable language attitude change, with status stereotypes typically more difficult to change than solidarity stereotypes (Genesee \& Holobow, 1989; Woolard \& Gahng, 1980).

Other research in this area consists of one-off studies testing the effectiveness of specific (typically idiosyncratic) interventions at improving language attitudes. For example, educating people about their biases via dialect awareness training (Bozoglan \& Gok, 2016; Wolfram \& Shilling, 2015) and/or explicitly instructing them to not let their biases influence their evaluations (Roessel et al., 2019) both appear to attenuate the evaluative downgrading of 
foreign-accented speakers. Inducing people to engage in perspective-taking with respect to foreign-accented speakers - either through imagined (Weyant, 2007) or direct experience speaking a foreign language (Hansen et al., 2014)—also appears to be effective. Likewise, structured intergroup contact with foreign-accented speakers (Kang et al., 2014) and interventions which increase the ease with which listeners process foreign-accented speech (Dragojevic, 2020) have also had success. Other interventions have focused on promoting an inclusive group identity. For instance, inducing participants to recategorize outgroup regionalaccented speakers in terms of a common ingroup identity increases listeners' sense of connection with those speakers and promotes more favorable evaluations (Abrams \& Hogg, 1987;

Dragojevic \& Giles, 2014). Interestingly, imitating an unfamiliar regional accent also appears to reduce bias, perhaps by facilitating perspective-taking and/or making a common ingroup identity salient (Adank et al., 2013).

\section{Summary}

As the foregoing attests, people make a wide range of judgments about others simply based on how they speak (documentation). Those judgments emerge early in life (development) and are the product of various causal mechanisms (explanation). They can have a wide range of effects, including prejudice and discrimination (consequences), some of which can be attenuated through various interventions (change).

\section{Moving Forward}

While we know a great deal about how and why people evaluate different language varieties and what consequences follow from those evaluations, there is still much to learn, and the years ahead offer a number of opportunities and challenges. 


\section{Approach}

Different disciplines have studied language attitudes using different perspectives and methodologies. On the one hand, this reflects the multidisciplinary nature of this topic and has given rise to a diverse and robust literature. On the other hand, it has resulted in the creation of disciplinary and methodological silos, which rarely communicate with one another. Moving forward, an interdisciplinary approach could help break down some of these barriers and further propel theoretical development, as well as promote social change. For instance, adopting a historical perspective may allow us to better understand how and why attitudes toward some varieties have changed over time (e.g., due to policies, norms; see Genesee \& Holobow, 1989; Woolard \& Gahng, 1990) and, hence, provide additional insight about why other varieties continue to be negatively evaluated today (see Hegarty, 2020). Similarly, better integration of the five lines of research described above would be fruitful. For instance, increased attention to the causal mechanisms underlying language attitudes (explanation) can facilitate the design and implementation of more effective interventions (change), which, in turn, can help reduce language-based prejudice and discrimination (consequences).

\section{Methodology}

Integrating new methodological approaches with theories would also help disentangle the language attitudes processes. For instance, a growing body of research is now using the voice averaging approach — which involves voice morphing - to test the impact of stereotypical speech on person perception (see Kachel et al., 2018). This approach may be useful to further

test the role of social categorisation and stereotyping in the language attitudes process (see Blair et al., 2002). Related, the use of big data could help us document how language attitudes are expressed in a wider range of contexts (e.g., social media; Durham, 2016), as well as provide us 
with a better understanding of how language attitudes change over time. More longitudinal research would also be helpful in this respect. While we know that specific interventions are effective at promoting language attitude change, it remains unclear to what extent those changes persist over time.

More consistency in the way studies approach language attitudes could also be beneficial. For instance, studies relying on vocal stimuli often do not measure listeners' perceptions of speakers' social group memberships, making it difficult to interpret findings, compare results across studies, and fully understand underlying processes (e.g., categorization, stereotyping). In light of this, future studies utilizing vocal stimuli should measure and report listeners' perceptions of speakers' social group memberships whenever possible (see Preston, 1989). This — coupled with the development of additional 'best practice guidelines' — would not only provide researchers with a standard procedure to follow but would also facilitate study comparison and replicability.

\section{Intersectionality}

More attention should also be devoted to intersectionality (see Levon, 2015). People belong to many different social categories, each of which may be conveyed by one or more vocal and nonvocal cues; how the intersectionality of these different identities influences social categorization and speaker perceptions remains understudied in the language attitudes literature (but see Rakić et al., 2020). For example, work by Campbell-Kibler $(2007,2011)$ has shown that, when vocal cues associated with different identities intersect, listeners form complex impression of speakers and may privilege some vocal cues over others when judging certain characteristics. It could be interesting to examine whether speakers whose voice simultaneously indexes multiple stigmatized identities (e.g., gay, ethnic minority) are subject to stronger discrimination than 
speakers whose voice indexes only a single stigmatized identity. Considering all these aspects in tandem is particularly important for the design and implementation of successful, theoreticallygrounded interventions.

\section{Target perspective}

Past research has primarily focused on the listener's perspective, documenting how people react to others' speech. Gluszek and Dovidio (2010a) have advocated for more focus on the speaker's perspective, examining how speakers - particularly those who use low prestige varieties - perceive and evaluate their own speech. Indeed, nonstandard accented speakers expect to be stereotyped and discriminated because of their accent (Derwing, 2003). Similarly, gay and lesbian speakers who believe they sound gender-atypical expect to be categorized as gay by others (Fasoli et al., 2018). This not only has detrimental effects on speakers' psychological well-being and social functioning (Birney et al., 2020; Gluszek \& Dovidio, 2010b; Lippi-Green, 2012), but also implies that speakers need to navigate stigma, or at least stigma expectations. One way speakers try to cope with stigma is by modulating their speech to either communicate or conceal their social identity (Giles, 2016). This has been observed among both nonstandardaccented (Moyer, 2007) and gay speakers (Daniele et al., 2020). However, such behaviorwhether conscious or unconscious - is potentially stressful. Hence, interventions should focus not only on reducing discrimination toward speakers of low prestige varieties, but also on helping to improve the well-being of those speakers who have to cope with and navigate prejudice and discrimination.

\section{Conclusion}

Collectively, the language attitudes literature has provided us with a rich understanding of the language attitudes process and contributed to our understanding of both intra- and 
intergroup relations. Future research will undoubtedly further refine our understanding of this important topic and, we hope, help promote social change that reduces language-based prejudice and discrimination. Toward that end - and as we approach a century of social-scientific research on language attitudes - we hope to see the emergence of a more unified language attitudes field in which scholars from different research areas and disciplines, and with different methodological skills, come together and integrate their research to work toward a common goal. 


\section{Acknowledgements}

We would like to thank the editors-Howie Giles and Karolina Hansen — and our two reviewers-Stephanie Lindemann and Janin Roessel—for their insightful feedback on an earlier version of this paper. 


\section{References}

Abrams, D., \& Hogg, M. A. (1987). Language attitudes, frames of reference, and social identity: A Scottish dimension. Journal of Language and Social Psychology, 6(3-4), 201-213. https://doi.org/10.1177/0261927X8763004

Adank, P., Stewart, A. J., Connell, L., \& Wood, J. (2013). Accent imitation positively affects language attitudes. Frontiers in Psychology, 4, Article 280. https://doi.org/10.3389/fpsyg.2013.00280

Albarracin, D., \& Shavitt, S. (2018). Attitudes and attitude change. Annual Review of Psychology, 69, 299-327. https://doi.org/10.1146/annurev-psych-122216-011911

Allport, G. W., \& Cantril, H. (1934). Judging personality from voice. Journal of Social Psychology, 5, 37-55. https://doi.org/10.1080/00224545.1934.9921582

Birney, M. E., Rabinovich, A., Morton, T. A., Heath, H., \& Ashcroft, S. (2020). When speaking English is not enough: The consequences of language-based stigma for nonnative speakers. Journal of Language and Social Psychology, 39(1), 67-86. https://doi.org/10.1177/0261927X19883906

Blair, I. V., Judd, C. M., Sadler, M. S., \& Jenkins, C. (2002). The role of Afrocentric features in person perception: Judging by features and categories. Journal of Personality and Social Psychology, 83(1), 5-25. https://doi.org/10.1037/0022-3514.83.1.5

Bourhis, R. Y. (1984). Cross-cultural communication in Montreal: Two field studies since Bill 101. International Journal of the Sociology of Language, 46, 33-47. https://doi.org/10.1515/ijsl.1984.46.33

Bourhis, R. Y. (2019). Evaluating the impact of Bill 101 on the English-speaking communities of Quebec. Language Problems and Language Planning, 43, 198-229. 
Bourhis, R. Y., \& Giles, H. (1976). The language of cooperation in Wales: A field study. Language Sciences, 42, 13-16.

Bozoglan, H., \& Gok, D. (2016). Effects of mobile-assisted dialect awareness training on the dialect attitudes of prospective English language teachers. Journal of Multilingual and Multicultural Development, 38(9), 772-787.

https://doi.org/10.1080/01434632.2016.1260572

Bradac, J. J., \& Wisegarver, R. (1984). Ascribed status, lexical diversity, and accent:

Determinants of perceived status, solidarity, and control of speech style. Journal of Language and Social Psychology, 3(4), 239-255.

https://doi.org/10.1177/0261927X8400300401

Burgoon, J. K. (1993). Interpersonal expectations, expectancy violations, and emotional communication. Journal of Language and Social Psychology, 12(1-2), 30-48. https://doi.org/10.1177/0261927X93121003

Butler, J., Floccia, C., Goslin, J., \& Panneton, R. (2011). Infants' discrimination of familiar and unfamiliar accents in speech. Infancy, 16(4), 392-417. https://doi.org/10.1111/j.15327078.2010.00050.x

Campbell-Kibler, K. (2011). Intersecting variables and perceived sexual orientation in men. American Speech, 86(1), 52-68. https://doi.org/10.1215/00031283-1277510

Cargile, A. C., \& Giles, H. (1997). Understanding language attitudes: Exploring listener affect and identity. Language and Communication, 17(3), 195-217. https://doi.org/10.1016/S0271-5309(97)00016-5 
Carlson, H. K., \& McHenry, M. A. (2006). Effect of accent and dialect on employability. Journal of Employment Counseling, 43(2), 70-83. https://doi.org/10.1002/j.21611920.2006.tb00008.x

Choy, S. J., \& Dodd, H. D. (1976). Standard-English-speaking and nonstandard HawaiianEnglish-speaking children: Comprehension of both dialects and teachers' evaluations. Journal of Educational Psychology, 68(2), 184-193. https://doi.org/10.1037/00220663.68.2.184

Coupland, N., \& Bishop, H. (2007). Ideologized values for British accents. Journal of Sociolinguistics, 11(1), 74-93. https://doi.org/10.1111/j.1467-9841.2007.00311.x

Cramer, J. (2016). Contested Southernness: The linguistic production and perception of identities in the borderlands. Duke University Press.

Cramer, J., \& Montgomery, C. (Eds.). (2016). Cityscapes and perceptual dialectology. De Gruyter Mouton. https://doi.org/10.1515/9781614510086

Creber, C., \& Giles, H. (1983). Social context and language attitudes: The role of formalityinformality of the setting. Language Sciences, 5, 155-161. https://doi.org/10.1016/S03880001(83)80020-5

Cristia, A., Seidl, A., Vaughn, C., Schmale, R., Bradlow, A., \& Floccia, C. (2012). Linguistic processing of accented speech across the lifespan. Frontiers in Psychology, 3, Article 479. https://doi.org/10.3389/fpsyg.2012.00479

Dailey, R. M., Giles, H., \& Jansma, L. L. (2005). Language attitudes in an Anglo-Hispanic context: The role of the linguistic landscape. Language and Communication, 25(1), 2738. https://doi.org/10.1016/j.langcom.2004.04.004 
Daniele, M., Fasoli, F., Antonio, R., Sulpizio, S., \& Maass, A. (2020). Gay voice: Stable marker of sexual orientation or flexible communication device? Archives of Sexual Behavior, 49, 2585-2600. https://doi.org/10.1007/s10508-020-01771-2

Day, R. R. (1982). Children's attitudes toward language. In E. B. Ryan \& H. Giles (Eds.), Attitudes toward language variation: Social and applied contexts (pp. 116-131). Edward Arnold.

Derwing, T. M. (2003). What do ESL students say about their accents? Canadian Modern Language Review, 59(4), 547-566. https://doi.org/10.3138/cmlr.59.4.547

Dixon, J. A., \& Mahoney, B. (2004). The effect of accent evaluation and evidence on a suspect's perceived guilt and criminality. Journal of Social Psychology, 144(1), 63-73. https://doi.org/10.3200/SOCP.144.1.63-73

Dixon, J. A., Mahoney, B., \& Cocks, R. (2002). Accents of guilt? Effects of regional accent, race, and crime type on attributions of guilt. Journal of Language and Social Psychology, 21(2), 162-168. https://doi.org/10.1177/02627X02021002004

Dixon, J. A., Tredoux, C. G., Durrheim, K., \& Foster, D. H. (1994). The role of speech accommodation and crime type in attribution of guilt. The Journal of Social Psychology, 134(4), 465-473. https://doi.org/10.1080/00224545.1994.9712197

Dobrow, J. R., \& Gidney, C. L. (1998). The good, the bad, and the foreign: The use of dialects in children's animated television. Annals of the American Academy of Political Sciences, 557(1), 105-119. https://doi.org/10.1177/0002716298557000009

Dovidio, J. F., \& Gluszek, A. (2012). Accent, nonverbal behavior, and intergroup bias. In H. Giles (Ed.), The handbook of intergroup communication (pp. 87-99). Routledge. 
Dragojevic, M. (2018). Language attitudes. In H. Giles \& J. Harwood (Eds.), Oxford research Encyclopedia of intergroup communication (Vol. 2, pp. 179-192). Oxford University Press. https://doi.org/10.1093/acrefore/9780190228613.013.437

Dragojevic, M. (2020). Extending the fluency principle: Factors that increase listeners' processing fluency positively bias their language attitudes. Communication Monographs, 87(2), 158-178. https://doi.org/10.1080/03637751.2019.1663543

Dragojevic, M., Berglund, C., \& Blauvelt, T. (2018). Figuring out who's who: The role of social categorization in the language attitudes process. Journal of Language and Social Psychology, 37(1), 28-50. https://doi.org/10.1177/0261927X17706942

Dragojevic, M., \& Giles, H. (2014). The reference frame effect: An intergroup perspective on language attitudes. Human Communication Research, 40(1), 91-111. https://doi.org/10.1111/hcre.12017

Dragojevic, M., \& Giles, H. (2016). I don't like you because you're hard to understand: The role of processing fluency in the language attitudes process. Human Communication Research, 42(3), 396-420. https://doi.org/10.1111/hcre.12079

Dragojevic, M., Giles, H., Beck, A-C., \& Tatum, N. T. (2017). The fluency principle: Why foreign accent strength negatively biases language attitudes. Communication Monographs, 84(3), 385-405. https://doi.org/10.1111/hcre.12079

Dragojevic, M., Mastro, D., Giles, H., \& Sink, A. (2016). Silencing nonstandard speakers: A content analysis of accent portrayals on American primetime television. Language in Society, 45(1), 59-85. https://doi.org/10.1017/S0047404515000743 
Dragojevic, M., Savage, M. W., Scott, A. M., \& McGinnis, T. (2020). Promoting oral health in Appalachia: Effects of threat label and source accent on message acceptance. Health Communication, 35(3), 297-307. https://doi.org/10.1080/10410236.2018.1560581

Eckert, P. (2008). Variation and the indexical field. Journal of Sociolinguistics, 12(4), 453-476. https://doi.org/10.1111/j.1467-9841.2008.00374.x

Fasoli, F., \& Hegarty, P. (2020). A leader doesn't sound lesbian! The impact of sexual orientation vocal cues on heterosexual persons' first impression and hiring decision. Psychology of Women Quarterly, 44(2), 234-255. https://doi.org/10.1177/0361684319891168

Fasoli, F., Hegarty, P., Maass, A., \& Antonio, R. (2018). Who wants to sound straight? Sexual majority and minority stereotypes, beliefs and desires about auditory gaydar. Personality and Individual Differences, 130(1), 59-64. https://doi.org/10.1016/j.paid.2018.03.046

Fazio, R. H., \& Olson, M. A. (2003). Attitudes: Foundations, functions, and consequences. In M. A. Hogg \& J. Cooper (Eds.), The Sage handbook of social psychology (pp. 139-160). Sage.

Fishbein M., \& Ajzen I. (1975). Belief, Attitude, Intention, and Behavior: An Introduction to Theory and Research. Addison-Wesley.

Fiske, S. T., Cuddy, A. J. C., Glick, P., \& Xu, J. (2002). A model of (often mixed) stereotype content: Competence and warmth respectively follow from perceived status and competition. Journal of Personality and Social Psychology, 82(6), 878-902. https://doi.org/10.1037/0022-3514.82.6.878 
Frumkin, L. (2007). Influences of accent and ethnic background on perceptions of eyewitness testimony. Psychology, Crime, \& Law, 13(3), 317-331. https://doi.org/10.1080/10683160600822246

Fuertes, J. N., Gottdiener, W., Martin, H., Gilbert, T. C., \& Giles, H. (2012). A meta- analysis of the effects of speakers' accents on interpersonal evaluations. European Journal of Social Psychology, 42(1), 120-133. https://doi.org/10.1002/ejsp.862

Gallois, C., Callan, V. J., \& Johnstone, M. (1984). Personality judgments of Australian Aborigine and whit speakers: Ethnicity, sex, and context. Journal of Language and Social Psychology, 3(1), 39-57. https://doi.org/10.1177/0261927X8431003

Gardner, R. C. (1982). Language attitudes and language learning. In E. B. Ryan \& H. Giles (Eds.), Attitudes towards language variation: Social and applied contexts (pp. 132-147). Edward Arnold.

Garrett, P. (2010). Attitudes to language. Cambridge University Press. https://doi.org/10.1017/CBO9780511844713

Gass, S., \& Varonis, E. M. (1984). The effect of familiarity on the comprehensibility of nonnative speech. Language Learning, 34(1), 65-87. https://doi.org/10.1111/j.14671770.1984.tb00996.x

Genesee, F., \& Bourhis, R. Y. (1982). The social psychological significance of code switching in cross-cultural communication. Journal of Language and Social Psychology, 1(1), 1-27. https://doi.org/10.1177/0261927X8200100102

Genesee, F., \& Holobow, N. E. (1989). Change and stability in intergroup perceptions. Journal of Language and Social Psychology, 8(1), 17-38.

https://doi.org/10.1177/0261927X8900800102 
Gibbons, P., Busch, J., \& Bradac, J. J. (1991). Powerful versus powerless language: Consequences for persuasion, impression formation, and cognitive response. Journal of Language and Social Psychology, 10(2), 115-133. https://doi.org/10.1177/0261927X91102003

Giles, H. (Ed.). (2016). Communication accommodation theory: Negotiating personal relationships and social identities across contexts. Cambridge University Press. https://doi.org/10.1017/CBO9781316226537

Giles, H. (in press). Forward: The vitality of language attitudes. In R. Kircher \& L. Zipp (Eds.), Research methods in language attitudes. Cambridge University Press.

Giles, H., Baker, S., \& Fielding, G. (1975). Communication length as a behavioral index of accent prejudice. International Journal of the Sociology of Language, 6, 73-81. https://doi.org/ https://doi.org/10.1515/ijsl.1975.6.73

Giles, H., \& Marlow, M. (2011). Theorizing language attitudes: Existing frameworks, an integrative model, and new directions. Annals of the International Communication Association, 35(1), 161-197. https://doi.org/10.1080/23808985.2011.11679116

Giles, H., \& Niedzielski, N. (1998). Italian is beautiful, German is ugly. In L. Bauer \& P. Trudgill (Eds.), Language myths (pp. 85-93). Penguin.

Giles, H., \& Watson, B. (Eds.). (2013). The social meanings of language, dialect, and accent: International perspectives on speech styles. Peter Lang.

Giles, H., Williams, A., Mackie, D. E., \& Rosselli, F. (1995). Reactions to Anglo- and HispanicAmerican-accented speakers: Affect, identity, persuasion, and the English-only controversy. Language and Communication, 15(2), 107-120. https://doi.org/10.1016/0271-5309(94)00019-9 
Giles, H., Wilson, P., \& Conway, T. (1981). Accent and lexical diversity as determinants of impression formation and perceived employment suitability. Language Sciences, 3(1), 91-103. https://doi.org/10.1016/S0388-0001(81)80015-0

Gill, M. M. (1994). Accent and stereotypes: Their effect on perceptions of teachers and lecture comprehension. Journal of Applied Communication Research, 22(4), 348-361. https://doi.org/10.1080/00909889409365409

Gluszek, A., \& Dovidio, F. J. (2010a). Speaking with a nonnative accent: Perception of bias, communication difficulties, and belonging in the United States. Journal of Language and Social Psychology, 29(2), 224-234. https://doi.org/10.1177/0261927X09359590

Gluszek, A., \& Dovidio, J. F. (2010b). The way they speak: A social psychological perspective on the stigma of nonnative accents in communication. Personality and Social Psychology Review, 14(2), 214-f237. https://doi.org/10.1177/1088868309359288

Hammine, M. (2020). Educated not to speak our language: Language attitudes and newspeakerness in the Yaeyaman language. Journal of Language, Identity \& Education. Advance online: https://doi.org/10.1080/15348458.2020.1753200

Hansen, K., \& Dovidio, J. F. (2016). Social dominance orientation, nonnative accents, and hiring recommendations. Cultural Diversity and Ethnic Minority Psychology, 22(4), 544-551. https://doi.org/10.1037/cdp0000101

Hansen, K., Rakić, T., \& Steffens, M. C. (2014). When actions speak louder than words: Preventing discrimination of nonstandard speakers. Journal of Language and Social Psychology, 33(1), 68-77. https://doi.org/10.1177/0261927X13499761 
Hansen, K., Rakić, T., \& Steffens, M. C. (2018). Foreign-looking native-accented people: More competent when first seen rather than heard. Social Psychological and Personality Science, 9(8), 1001-1009. https://doi.org/10.1177/1948550617732389

Hegarty, P. (2020). Strangers and states: Situating accentism in a world of nations. Journal of Language and Social Psychology, 39(1), 172-179. https://doi.org/10.1177/0261927X19884093

Hendriks, B., van Meurs, F., \& Reimer, A.-K. (2018). The evaluation of lecturers' nonnativeaccented English: Dutch and German students' evaluations of different degrees of Dutchaccented and German-accented English of lecturers in higher education. Journal of English for Academic Purposes, 34, 28-45. https://doi.org/10.1016/j.jeap.2018.03.001

Hirschfeld, L. A., \& Gelman, S. A. (1997). What young children think about the relationship between language variation and social difference. Cognitive Development, 12(2), 213238. https://doi.org/10.1016/S0885-2014(97)90014-9

Hoenigswald, H. (1966) A proposal for the study of folk-linguistics. In W. Bright (Ed.), Sociolinguistics (pp. 16-26). Mouton.

Kachel, S., Radtke, A., Skuk, V. G., Zäske, R., Simpson, A. P., \& Steffens, M. C. (2018) Investigating the common set of acoustic parameters in sexual orientation groups: A voice averaging approach. PLoS ONE, 13, e0208686. https://doi.org/10.1371/journal.pone.0208686

Kang, O. Rubin, D., \& Lindemann, S. (2014). Mitigating U.S. undergraduates' attitudes toward international teaching assistants. TESOL Quarterly, 49(4), 681-706. https://doi.org/10.1002/tesq. 192 
Kervyn, N., Fiske, S., \& Yzerbyt, V. (2015). Forecasting the primary dimension of social perception: Symbolic and realistic threats together predict warmth in the stereotype content model. Social Psychology, 46(1), 36-45. https://doi.org/10.1027/18649335/a000219

Kinzler, K. D., Corriveau, K. H., \& Harris, P. L. (2011). Children's selective trust in nativeaccented speakers. Developmental Science, 14(1), 106-111. https://doi.org/10.1111/j.1467-7687.2010.00965.x

Kinzler, K. D., \& DeJesus, J. M. (2013). Northern = smart and Southern = nice: The development of accent attitudes in the United States. The Quarterly Journal of Experimental Psychology, 66(6), 1146-1158.

https://doi.org/10.1080/17470218.2012.731695

Kinzler, K. D., Dupoux, E., \& Spelke, E. S. (2007). The native language of social cognition. National Proceedings of the National Academy of Sciences of the United States of America, 104(30), 12577-12580. https://doi.org/10.1073/pnas.0705345104

Kinzler, K. D., Shutts, K., \& Correll, J. (2010). Priorities in social categories. European Journal of Social Psychology, 40(4), 581-592. https://doi.org/10.1002/ejsp.739

Kinzler, K. D., Shutts, K., DeJesus, J., \& Spelke, E. S. (2009). Accents trumps race in guiding children's social preferences. Social Cognition, 27(4), 623-634. https://doi.org/10.1521/soco.2009.27.4.623

Labov, W. (1966). The social stratification of English in New York City. Center for Applied Linguistics. 
Lambert, W. E., Hodgson, R. C., Gardner, R. C., \& Fillenbaum, S. (1960). Evaluational reactions to spoken languages. Journal of Abnormal and Social Psychology, 60(1), 44-51. https://doi.org/10.1037/h0044430

Landry, R., \& Bourhis, R. Y. (1997). Linguistic landscape and ethnolinguistic vitality: An empirical study. Journal of Language and Social Psychology, 16(1), 23-49. https://doi.org/10.1177/0261927X970161002

Levin, H., Giles, H., \& Garrett, P. (1994). The effects of lexical formality on accent and trait attributions. Language and Communication, 14(3), 265-274. https://doi.org/10.1016/0271-5309(94)90004-3

Levon, E. (2015). Integrating intersectionality in language, gender, and sexuality research. Language and Linguistic Compass, 9(7), 295-308. https://doi.org/10.1111/lnc3.12147

Liebscher, G., \& Dailey-O’Cain, J. (2009). Language attitudes in interaction. Journal of Sociolinguistics, 12(2), 195-222. https://doi.org/10.1111/j.1467-9841.2009.00404.x

Lindemann, S. (2003). Koreans, Chinese or Indians? Attitudes and ideologies about non- native English speakers in the United States. Journal of Sociolinguistics, 7(3), 348-364. https://doi.org/10.1111/1467-9481.00228

Lindemann, S. (2005). Who speaks “broken English”? US undergraduates' perceptions of nonnative English. International Journal of Applied Linguistics, 15(2), 187-212. https://doi.org/10.1111/j.1473-4192.2005.00087.x

Lippi-Green, R. (2012). English with an accent: Language, ideology, and discrimination in the United States (2nd ed.). Routledge.

Luhman, R. (1990). Appalachian English stereotypes: Language attitudes in Kentucky. Language in Society, 19(3), 331-348. https://doi.org/10.1017/S0047404500014548 
Marlow, M. L., \& Giles, H. (2010). “We won't get ahead speaking like that!” Expressing and managing language criticism in Hawai'i. Journal of Multilingual and Multicultural Development, 31(3), 237-251. https://doi.org/10.1080/01434630903582714

Mastro, D. E. (2009). Racial/ethnic stereotyping and the media. In R. Nabi \& M. B. Oliver (Eds.), The SAGE handbook of media processes and effects (pp. 377-392). Sage.

Mehler, J., Jusczyk, P., Lambertz, G., Halsted, N., Bertoncini, J., Amiel-Tison, C. (1988). A precursor of language acquisition in young infants. Cognition, 29(2), 143-178. https://doi.org/10.1016/0010-0277(88)90035-2

McGowan, K. B. (2015). Social expectation improves speech perception in noise. Language and Speech, 58(4), 502-521. https://doi.org/10.1177/0023830914565191

McKenzie, R. M., \& Carrie, E. (2018). Implicit-explicit attitudinal discrepancy and the investigation of language attitude change in progress. Journal of Multilingual and Multicultural Development, 39(9), 830-844. https://doi.org/10.1080/01434632.2018.1445744

Milroy, J., \& Milroy, L. (1999). Authority in language: Investigating Standard English (3rd ed.). Routledge.

Moyer, A. (2007). Do language attitudes determine accent? A study of bilinguals in the USA. Journal of Multilingual and Multicultural Development, 28(6), 502-518. https://doi.org/10.2167/jmmd514.0

Munro, M. J. (1998). The effects of noise on the intelligibility of foreign-accented speech. Studies in Second Language Acquisition, 20(2), 139-154. https://doi.org/10.1017/S027226319800202

Pear, T. H. (1931). Voice and personality. Wiley. 
Preston, D. R. (1989). Perceptual dialectology: Nonlinguists' views of areal linguistics. Foris.

Rakić, T., Steffens, M. C., \& Mummendey, A. (2011a). Blinded by the accent! The minor role of looks in ethnic categorization. Journal of Personality and Social Psychology, 100(1), 1629. https://doi.org/10.1037/a0021522

Rakić, T., Steffens, M. C., \& Mummendey, A. (2011b). When it matters how you pronounce it: The influence of regional accents on job interview outcome. British Journal of Psychology, 102(4), 868-883. https://doi.org/10.1111/j.2044-8295.2011.02051.x

Rakić, R., Steffens, M. C., \& Sazegar, A. (2020). Do people remember what is prototypical? The role of accent-religion intersectionality for individual and category memory. Journal of Language and Social Psychology, 39(4), 476-494.

https://doi.org/10.1177/0261927X20933330

Rodriguez, J. I., Cargile, A. C., \& Rich, M. D. (2004). Reactions to African-American Vernacular English: Do more phonological features matter? The Western Journal of Black Studies, 28(3), 407-414.

Roessel, J., Schoel, C., \& Stahlberg, D. (2018). What's in an accent? General spontaneous biases against nonnative accents: An investigation with conceptual and auditory IATs. European Journal of Social Psychology, 48(4), 535-550. https://doi.org/10.1002/ejsp.2339

Roessel, J., Schoel, C., \& Stahlberg, D. (2020). Modern notions or accent-ism: Findings, conceptualizations, and implications for interventions and research on nonnative accents. Journal of Language and Social Psychology, 39(1), 87-111. https://doi.org/10.1177/0261927X19884619 
Roessel, J., Schoel, C., Zimmermann, R., \& Stahlberg, D. (2019). Shedding new light on the evaluation of accented speakers: Basic mechanisms behind nonnative listeners' evaluations of nonnative accented job candidates. Journal of Language and Social Psychology, 38(1), 3-32. https://doi.org/10.1177/0261927X17747904

Rubin, D. L. (1992). Nonlanguage factors affecting undergraduates' judgments of nonnative English-speaking teaching assistants. Research in Higher Education, 33(4), 511-531. https://doi.org/ 10.1007/BF00973770

Rubin, D. L., \& Smith, K. A. (1990). Effects of accent, ethnicity, and lecture topic on undergraduates' perceptions of nonnative English-speaking teaching assistants. International Journal of Intercultural Relations, 14(3), 337-353. https://doi.org/10.1016/0147-1767(90)90019-S

Ryan, E. B. (1983). Social psychological mechanisms underlying native speaker evaluations of non-native speech. Studies in Second Language Acquisition, 5(2), 148159. https://doi.org/10.1017/S0272263100004824

Ryan, E. B., Hewstone, M., \& Giles, H. (1984). Language and intergroup attitudes. In J. R. Eiser (Ed.), Attitudinal judgments (pp. 135-160). Springer.

Schoel, C., Roessel, J., Eck, J., Janssen, J., Petrovic, B., Rothe, A., Rudert, S. C., \& Stahlberg, D. (2013). "Attitudes towards languages" (ATOL) scale: A global instrument. Journal of Language and Social Psychology, 32(1), 21-45. https://doi.org/10.1177/0261927X12457922

Subtirelu, N. C. (2015). "She does have an accent...but": Race and language ideology in students' evaluations of mathematics instructors on RateMyProfessors.com. Language in Society, 44(1), 35-62. https://doi.org/10.1017/S0047404514000736 
Tsalikis, J., DeShields, O. W., \& LaTour, M. S. (1991). The role of accent on the credibility and effectiveness of the salesperson. Journal of Personal Selling \& Sales Management, 11(1), 31-41. https://doi.org/ 10.1080/08853134.1991.10753857

Tucker, R., \& Lambert, W. E. (1969). White and Negro listeners' reactions to various AmericanEnglish dialects. Social Forces, 47(4), 463-468. https://doi.org/10.2307/2574535

Weyant, J. M. (2007). Perspective taking as a means of reducing negative stereotyping of individuals who speak English as a second language. Journal of Applied Social Psychology, 37(4), 703-716. https://doi.org/10.1111/j.1559-1816.2007.00181.x

Wolfram, W., \& Schilling, N. (2015). American English: Dialects and variation (3 ${ }^{\text {rd }}$ ed.). Wiley.

Woolard, K. A., \& Gahng, T. (1990). Changing language policies and attitudes in autonomous Catalonia. Language in Society, 19(3), 311330. https://doi.org/10.1017/S0047404500014536

Yook, C., \& Lindemann, S. (2013). The role of speaker identification in Korean university students' attitudes towards five varieties of English. Journal of Multilingual and Multicultural Development, 34(3), 279-296.

https://doi.org/10.1080/01434632.2012.734509

Zahn, C. J., \& Hopper, R. (1985). Measuring language attitudes: The speech evaluation instrument. Journal of Language and Social Psychology, 4(2), 113-123. https://doi.org/10.1177/0261927X8500400203 


\section{Author Biographies}

Marko Dragojevic (PhD, University of California, Santa Barbara) is an assistant professor in the Department of Communication at the University of Kentucky. His research focuses on language and interpersonal/intergroup communication.

Fabio Fasoli (PhD, University of Trento) is a lecturer in Social Psychology at the University of Surrey. His research interests regard social communication, LGBT discrimination, voice-based categorization and homophobic language.

Jennifer Cramer ( $\mathrm{PhD}$, University of Illinois at Urbana-Champaign) is an associate professor and department chair in the Department of Linguistics at the University of Kentucky. Her research focuses on the perception and production of regional linguistic identities in the United States.

Tamara Rakić (PhD, Friedrich Schiller University Jena) is a Lecturer in Social Psychology at Lancaster University, UK. Her research interests include the influence of accents on person perception, categorization, and accommodation; and different language and cross-cultural aspects of social psychology. 